Pak. j. sci. ind. res. Ser. A: phys. sci. 201356 (1) 34-41

\title{
Investigation of Flash Cure Process for Finishing Cotton
}

\author{
Iram Abdullah $^{\text {ab*, Syed Qummer Zia Gilani }}{ }^{\mathrm{b}}$ and Aula Khan ${ }^{\mathrm{c}}$ \\ ${ }^{a}$ University of Leeds, Leeds, UK \\ ${ }^{\mathrm{b}}$ Department of Textile Chemistry, National Textile University, Faisalabad-37610, Pakistan \\ ${ }^{\mathrm{c}}$ Masood Textile Mills Limited, Sheikupura Road, Faisalabad, Pakistan
}

(received May 24, 2011; revised February 28, 2012; accepted March 7, 2012)

\begin{abstract}
Easy-care performance is imparted to cotton fabric by the formation of crosslinks between the adjacent cellulose chains. The most widely accepted crosslinking method is treatment with $N$-methylol resins using sequential pad-dry-cure technique. Flash cure technique is also used to complete the crosslinking by single stage dry/cure cycle. As a result better tear and tensile properties are attained without the undesirable effect on crease recovery property. Such a curing system can be used for energy conservation or to reduce energy consumption in resin finishing of cotton fabrics.
\end{abstract}

Keywords: crosslinking, $N$-methylol, flash curing, easy-care properties

\section{Introduction}

Pad-dry-cure is the conventional procedure for imparting durable crease recovery properties to the cotton fabrics. The industrial pad-dry-cure procedure consists of impregnating the fabric with the aqueous solution of the crosslinking agents along with a suitable catalyst system, pre-drying, drying and then a subsequent curing step either on a stenter frame or drying on rollers and then curing in a stenter frame or on a semi-contact curing oven, after washing in one or more open width wash boxes. Finally, drying is done on drying rollers. High energy consumption occur during drying and curing operations and more energy is required for heavy weight fabrics. The common approach in textile industry to conserve energy is to complete drying and curing stage in a stenter frame. The afterwash, in many cases, is also omitted to save energy.

In 1980s the low wet pick-up techniques such as lick roller (Rowland et al., 1983a), transfer pad-cure (Varghese and Doshi, 1982) and foaming techniques (Gonzales and Reinhardt, 1986; Rowland et al., 1983b; Namboodri and Duke, 1979) were investigated to reduce the energy consumption in drying. The results were comparable to conventional pad-dry-cure system. However, commercially $35 \%$ wet pick-up was required to eliminate the pre-drying step. Furthermore, more than $20 \%$ reduction in resin add-on produced fabrics with lower durable press properties compared with

*Author for correspondence; E-mail: i_tayyab@hotmail.com pad-dry-cured fabrics (Wright, 1981). Since then industry has made significant advances in developing special finishing effects such as water repellency (Wadsworth and Wey, 1988), water proofing (Mukhopadhyay and Midha, 2008), fire retardency (Wadsworth and Wey, 1988) and garment finishing (Lambert and Harper, 1990) via foam application of finishing chemicals. The ultraviolet radiation was also investigated to cure fabrics. The radiation times were too long for commercial use and sophisticated safety equipment was required for workers for eye protection (Ferrero et al., 2008; Millington, 1998; Reinhardt and Harris, 1980).

Performing drying and curing in a single stage can conserve significant amount of energy, though very little information is available on single stage curing procedure. Pensa and Sello (1982) cured cotton fabric at $160^{\circ} \mathrm{C} / 30 \mathrm{sec}$ and indicated that high concentration of an active catalyst system is required to resin finish light to medium fabrics. The low wet pick-up technique was combined with a highly active catalyst system to perform the single stage curing of heavy drill fabrics at $170^{\circ} / \mathrm{min}$ (Varghese and Doshi, 1982).

The present work aims at finishing cotton fabric with most widely used $N$-methylol crosslinking agents using flash cure: a single stage curing procedure and conventional pad-dry-cure procedure. In this study flash/single stage curing technique has been compared with conventional pad-dry-cure technique. The treatment parameters of concentration of resin and catalyst, wet 
pick-up, drying and curing conditions were kept constant throughout the study to observe the effect of each process on fabric properties. To ensure resin crosslinking long curing time is used in combination with industrially used catalyst; magnesium chloride hexa-hydrate. The physical properties of treated fabric of dry crease recovery angle, tear strength and tensile strength after a domestic wash were also evaluated.

\section{Materials and Methods}

Materials. A $100 \%$ bleached plain cotton fabric of $64 \times 60 / 25 \times 24$ quality, obtained from Yarn Market Faisalabad, was used throughout this study; the fabric had been singed, desized, scoured, bleached and neutralized. Protorez R, the dimethylol dihydroxy ethylene urea (DMDHEU) based crosslinking agent, was obtained from Swiss Speciality Chemicals. Arkofix NZF; the dihydroxy ethylene urea (DHEU) based crosslinking agent was obtained from Clarient. Magnesium chloride hexa-hydrate was of general laboratory grade supplied by Merck Germany.

Fabric treatments. The fabric samples were treated in an aqueous bath containing $25,50,75$ and $100 \mathrm{~g} / \mathrm{dm}^{3}$ crosslinking agent and 5, 10,15 and $20 \mathrm{~g} / \mathrm{dm}^{3}$ catalyst (magnesium chloride hexa-hydrate), respectively. Acetic acid of general laboratory scale was used to maintain $\mathrm{pH}$ 4. The following two different treatment processes were used:

Pad-dry-cure (PDC) process. The fabric samples (30 $\times 42 \mathrm{~cm}^{2}$ ) were impregnated in the pad bath containing resin and catalyst for $5 \mathrm{~min}$. The samples were padded through the squeeze rollers of TSUJII padding mangle at a pressure of $4 \mathrm{kgf} / \mathrm{cm}^{2}$ to obtain $70-75 \%$ pick-up, then dried in TSUJII stenter for $3 \mathrm{~min}$ at $130{ }^{\circ} \mathrm{C}$, and finally cured for $3 \mathrm{~min}$ at $160^{\circ} \mathrm{C}$.

Flash cure (FC) process. The flash cure process is identical to PDC process, except that the drying and curing were performed in one step. The fabric samples were padded using the same padding conditions and then were cured at $160{ }^{\circ} \mathrm{C}$ for $3 \mathrm{~min}$.

Fabric evaluation. Prior to testing all fabric samples were conditioned at $65 \% \mathrm{RH}$ and $20^{\circ} \mathrm{C}$ for $24 \mathrm{~h}$. The easy-care properties of unwashed and five times washed samples were evaluated using standard procedures including dry crease recovery angle (DCRA; BS EN ISO 1956), tear strength (ASTM D 1424-96) and tensile strength (ASTM D 5035-06). The treated samples were washed using standard procedure BS
EN ISO 15487 at $40{ }^{\circ} \mathrm{C}$ for $100 \mathrm{~min}$. then samples were air dried.

\section{Results and Discussion}

Easy-care properties are produced by setting the fabric in the desired configuration via the formation of crosslinks between the adjacent cellulose chains. Dimethylol dihydroxy ethylene urea (DMDHEU) and Dihydroxy ethylene urea (DHEU) (Scheme 1) are the most commonly used crosslinking agents in the textile industry. Their effectiveness depends both on degree of crosslinking and the condition of the fibre at the time when the crosslinks are formed. In pad-dry-cure procedure the crosslinking is attained in the collapse state of the fibre in the presence of an acid catalyst. There is a close relationship between the chemical constitution and properties of $N$-methylol compounds and fabrics finished with these compounds. Generally, it is accepted that hydroxyl groups of DMDHEU and DHEU both are capable of reacting with cellulose. DHEU being the bi-functional forms linear chains between two adjacent cellulose molecules while DMDHEU being the multi-functional forms three dimensional structure with one site reacted to cellulose. The ring hydroxyls of DHEU based resins only reacts with secondary cellulosic hydroxyls to form intramolecular crosslinks while the methylol groups of DMDHEU react preferentially with primary cellulosic hydroxyls to form intermolecular crosslinks. The ring hydroxyls of DMDHEU can also react with secondary cellulosic hydroxyls to form intramolecular crosslinks (Stevens and Smith, 1970; Petersen, 1968; Gonzales et al., 1966a; 1966b; Rollins et al., 1966). The structural factor which determines the reactivity of $\mathrm{N}$-methylol compounds is the electron density at the nitrogen atom. Compounds having high electron density at the nitrogen atom are particularly reactive i.e dimethylol dihydroxy
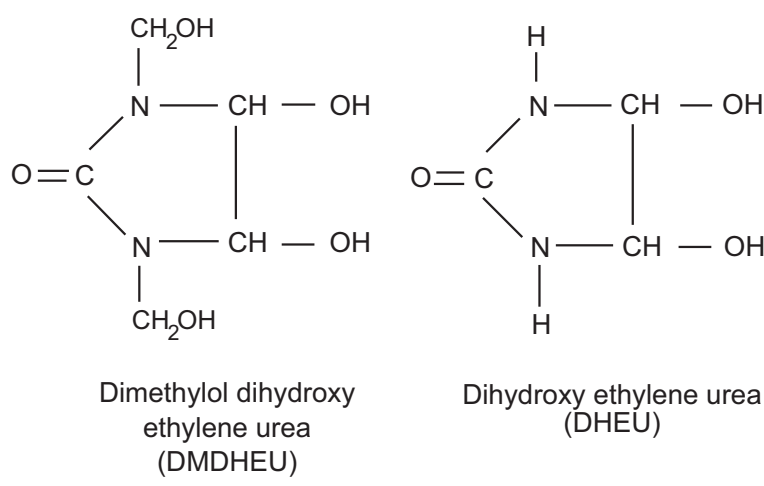

Dihydroxy ethylene urea (DHEU) 
ethylene urea reacts very rapidly because of its high electron density at the nitrogen atom compared to dimethylol dihydroxy ethylene urea which exhibits extraordinarily little reactivity in acid medium on account of low electron density (Petersen, 1968). The substitution in the neighbouring methylol group also plays main role in determining the reactivity of DMDHEU reagents with cellulose. However, the commercially prepared reagents have different reactivities because different products or geometric isomers are formed from the addition of urea, formaldehyde and glyoxal. The additives in commercial products can also activate or deactivate the resins reactivity towards cellulose.

Fabrics were treated with Protorez R and Arkofix NZF crosslinking agents using pad-dry-cure and flash cure procedure to observe the effect of different crosslinks on fabric easy-care properties. Furthermore, a 50:50 mixture of Protorez R/Arkofix NZF/crosslinking agents was applied to observe the change in easy-care properties

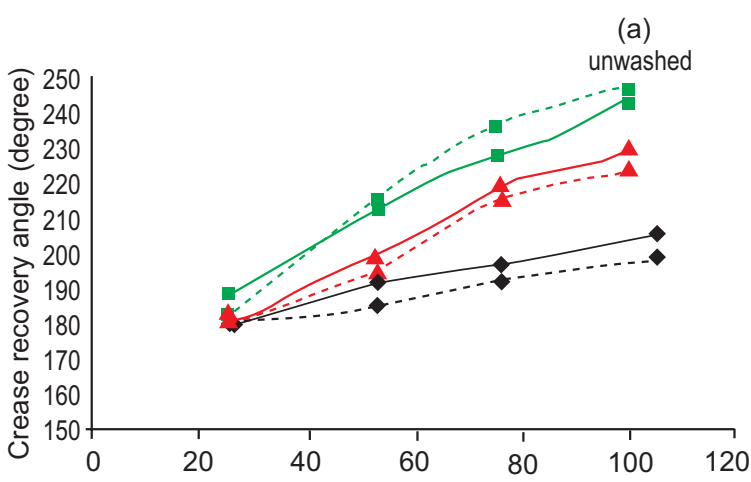

(b)

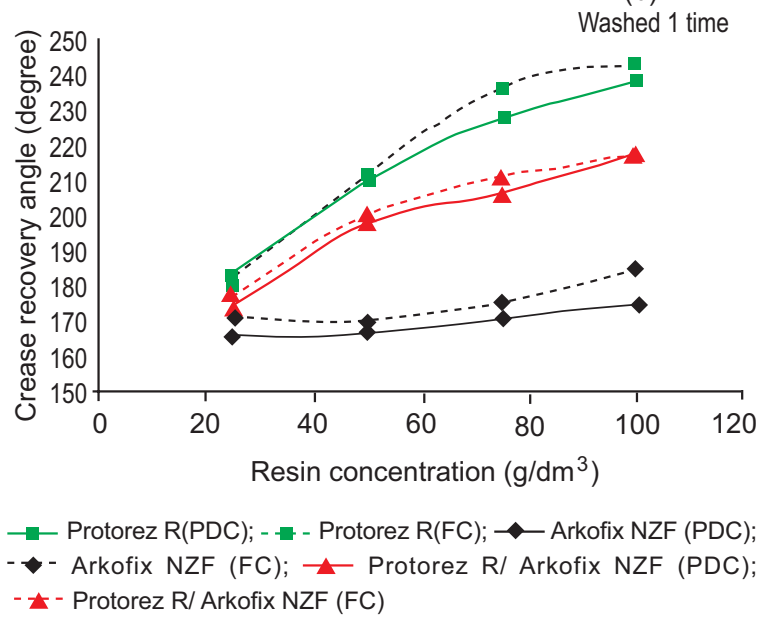

Fig. 1. Crease recovery angle values of (a) Unwashed and (b) 1 time washed; paddry-cured and flash cured fabrics Vs resin concentration $\left(\mathrm{g} / \mathrm{dm}^{3}\right)$. compared to that of Protorez R and Arkofix NZF resin alone.

Crease recovery. Data on immediate crease recovery angle values of fabrics finished by PDC and FC procedures are shown in Fig. 1. The crease recovery angle values of fabrics treated differently are increased with the increase in resin concentration. However, crease recovery angle values of Protorez $\mathrm{R}$ treated fabrics are better than crease recovery angle values of Arkofix NZF treated fabrics, which support the concept that intra-molecular crosslinks formed by DHEU crosslinking agent are not as effective in enhancing the crease recovery of fabrics as intermolecular crosslinks formed by DMDHEU crosslinking agent. The addition of Protorez R resin into Arkofix NZF resin system improved the crease recovery angle values of treated fabrics due to the formation of inter-molecular crosslinks in combination with intra-molecular crosslinks.

Pad-dry-cure is the best known method of improving the crease recovery of cellulosic fabrics. Passing through the padding solution, swells the fibres, this breaks many of the hydrogen bonds, these bonds form to a greater or lesser degree due to collapsing of fibres during drying. Subsequently during high temperature curing, a stronger hydrogen bonding system is established along the ether linkages between the cellulose and crosslinking agent. At the same time, resin entanglements formed in the accessible regions replace some of the original hydrogen bonds between cellulose chains. This combination of normal hydrogen bonds, heat-generated hydrogen bonds and resin entanglements provide an elastic network which imparts recovery from creasing (Marsh, 1966; Steele, 1960). Performing drying and curing in one step, such as in a flash-cure process; the rate of crosslinking would be greater than the rate of diffusion of resin monomer into fibre interior. This caused deposition of resin on fibre surface. Deposition of Protorez R resin caused slight increase in crease recovery angle values while deposition of Arkofix NZF and Arkofix $\mathrm{NZF}$ /Protorez $\mathrm{R}$ resin systems caused slight decrease in crease recovery angle values. After a domestic wash the crease recovery angle values of flash cured fabrics are slightly better than that of pad-dry-cured fabrics.

Tear and tensile strength. As the crease recovery of fabrics was improved, their tear and tensile strength reduced regardless of different curing treatments and chemical compositions. These changes result as a natural consequence from the increase in fibre stiffness and 
reduction in fibre extensibility (Weigmann et al., 1969; Gagliardi and Gruntfest, 1950). The reduction in fibre extensibility results in yarns and fabrics which have less ability to distribute applied stresses in a tear, tensile, or ripping test. The tear and tensile strength values of pad-dry-cured and flash cured fabrics treated with Protorez R, Arkofix NZF and Protorez R/Arkofix NZF resin systems are compared in Figs. 2-3. The tear and tensile strength values of flash cured fabrics are higher than that of pad-dry-cured fabrics, however, there is a small difference between the tear and tensile strength values of Protorez R finished fabrics.
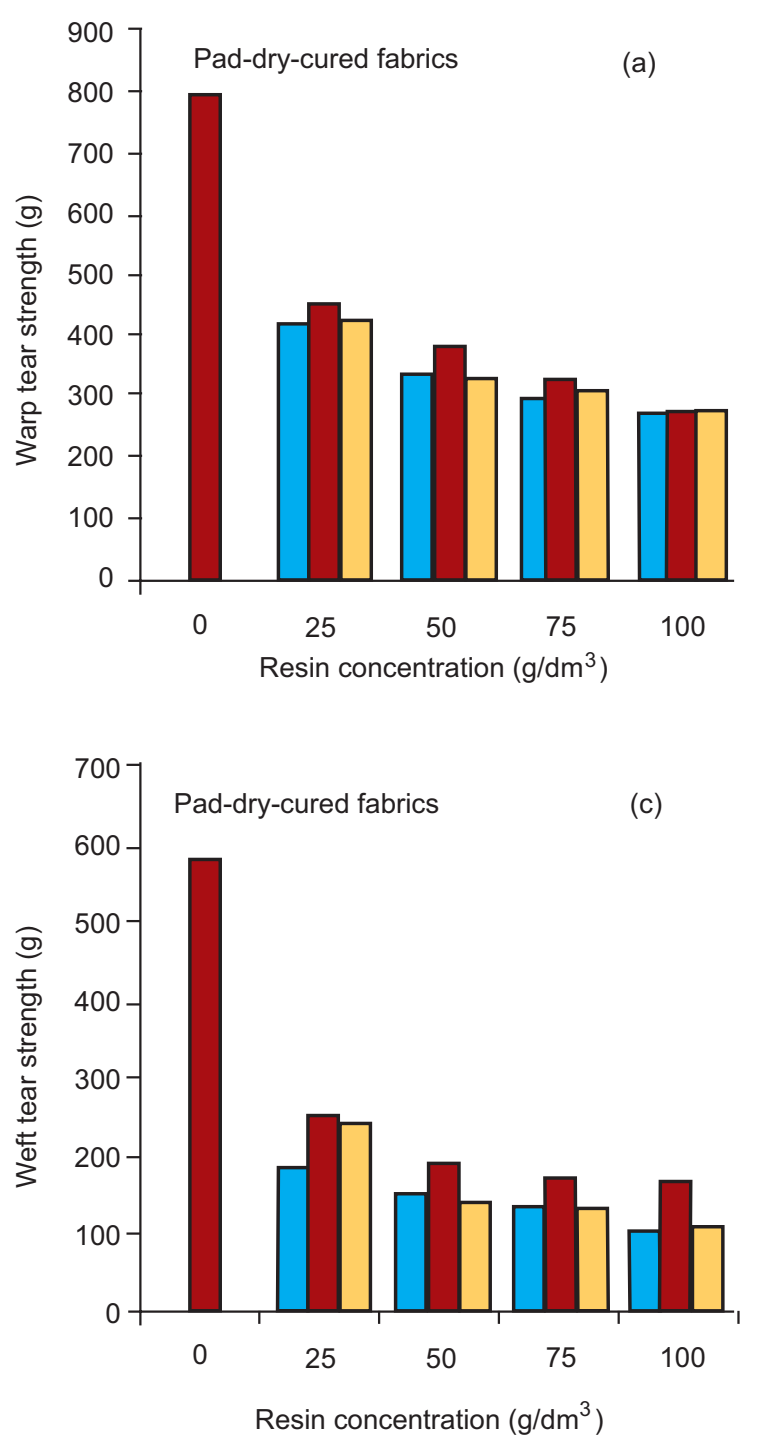

Protorez R
Arkofix NZF resin being bi-functional forms linear crosslinks between two adjacent cellulose chains. These crosslinks permit greater extensibility than three dimensional crosslinks formed by Protorez R resin. Due to this difference in nature of the crosslinks, the tear and tensile strength values of Arkofix NZF treated fabrics are better than that of Protorez R treated fabrics. Addition of Protorez R resin into Arkofix NZF resin system caused reduction in tear and tensile strength values compared to Arkofix NZF finished fabrics due to the introduction of stiff crosslinks into linear structure of Arkofiz NZF resin. After a domestic wash the tear
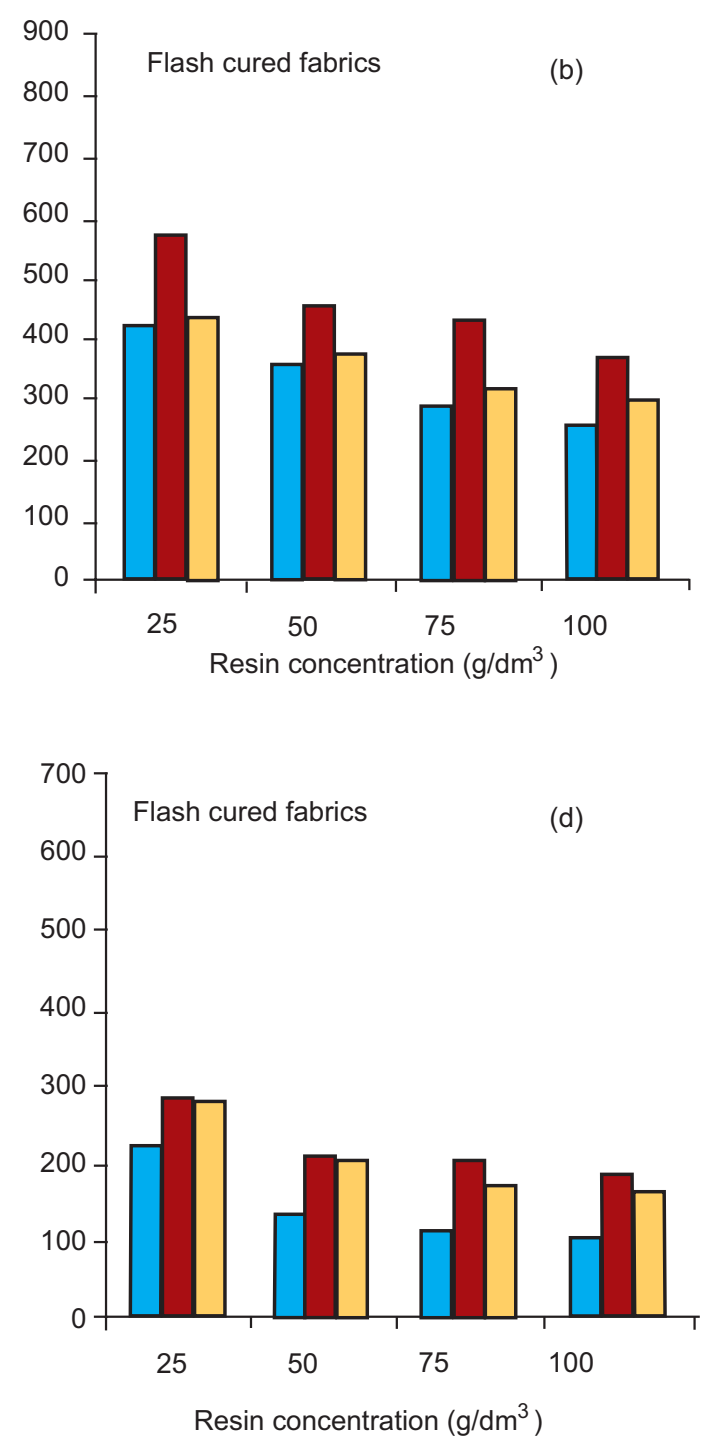

Fig. 2a-d. Tear strength values (g) of unwashed fabrics Vs resin concentration $\left(\mathrm{g} / \mathrm{dm}^{3}\right)$; (a) warp tear strength (g) values of pad-dry-cured fabrics, (b) warp tear strength (g) values of flash cured fabrics, (c) weft tear strength $(\mathrm{g})$ values of pad-dry-cured fabrics, $(\mathrm{d})$ weft tear strength $(\mathrm{g})$ values of flash cured fabrics. 

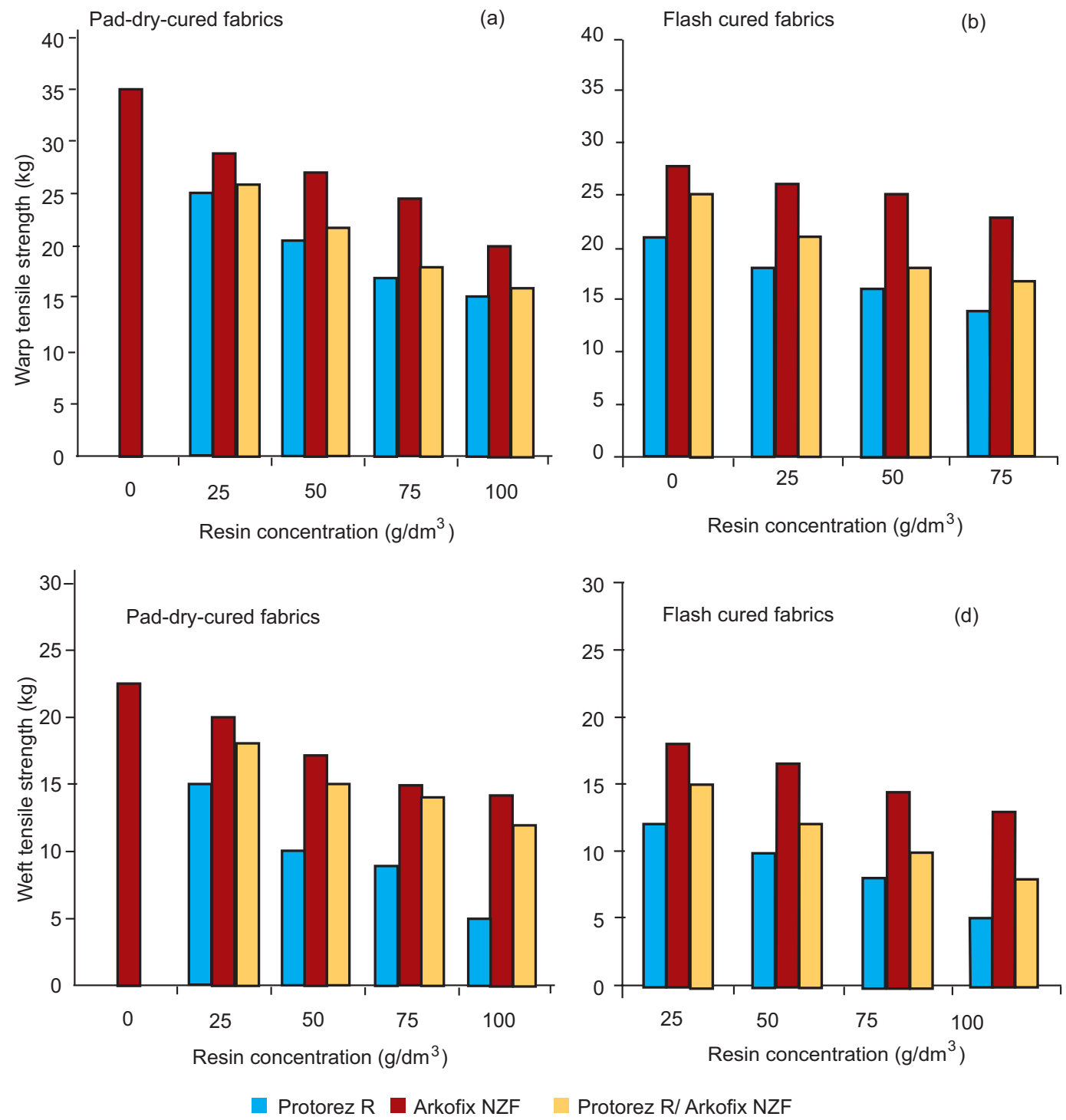

Fig. 3a-d. Tensile strength values ( $\mathrm{kg}$ ) of unwashed fabrics Vs resin concentration $\left(\mathrm{g} / \mathrm{dm}^{3}\right)$; (a) warp tensile strength $(\mathrm{kg})$ values of pad-dry-cured fabrics, (b) warp tensile strength $(\mathrm{kg})$ values of flash cured fabrics, (c) weft tensile strength $(\mathrm{kg})$ values of pad-dry-cured fabrics, (d) weft tensile strength $(\mathrm{kg})$ values of flash cured fabrics.

and tensile strength values are slightly improved. This might be due to the removal of surface resin as shown in Figs. 4-5.

The crosslink affects the stiffness or extensibility of fibres when chemically formed between two adjacent cellulose chains. Flash cure process facilitate the deposition of resin on the fibre surface which indicates that the ratio of self-crosslink polymer might be more than the ratio of covalent bonds formed between resin monomer and cellulose. Physical bonds permit greater extensibility than covalent bonds thus the tear and tensile strength values of flash cured fabrics are better than that of pad-dry-cured fabrics.

Fabric appearance. As Protorez R resin concentration is increased, the appearances of both pad-dry-cured and flash-cured fabric samples were improved as compared to original fabric, however, mild creases were observed on flash-cured fabrics. Arkofix NZF treated fabrics showed no improvement in physical appearance of fabric compared to original fabric; pad-dry-cured and flash-cured fabrics both appeared creased. The appearance of fabrics treated with Protorez P/Arkofix 

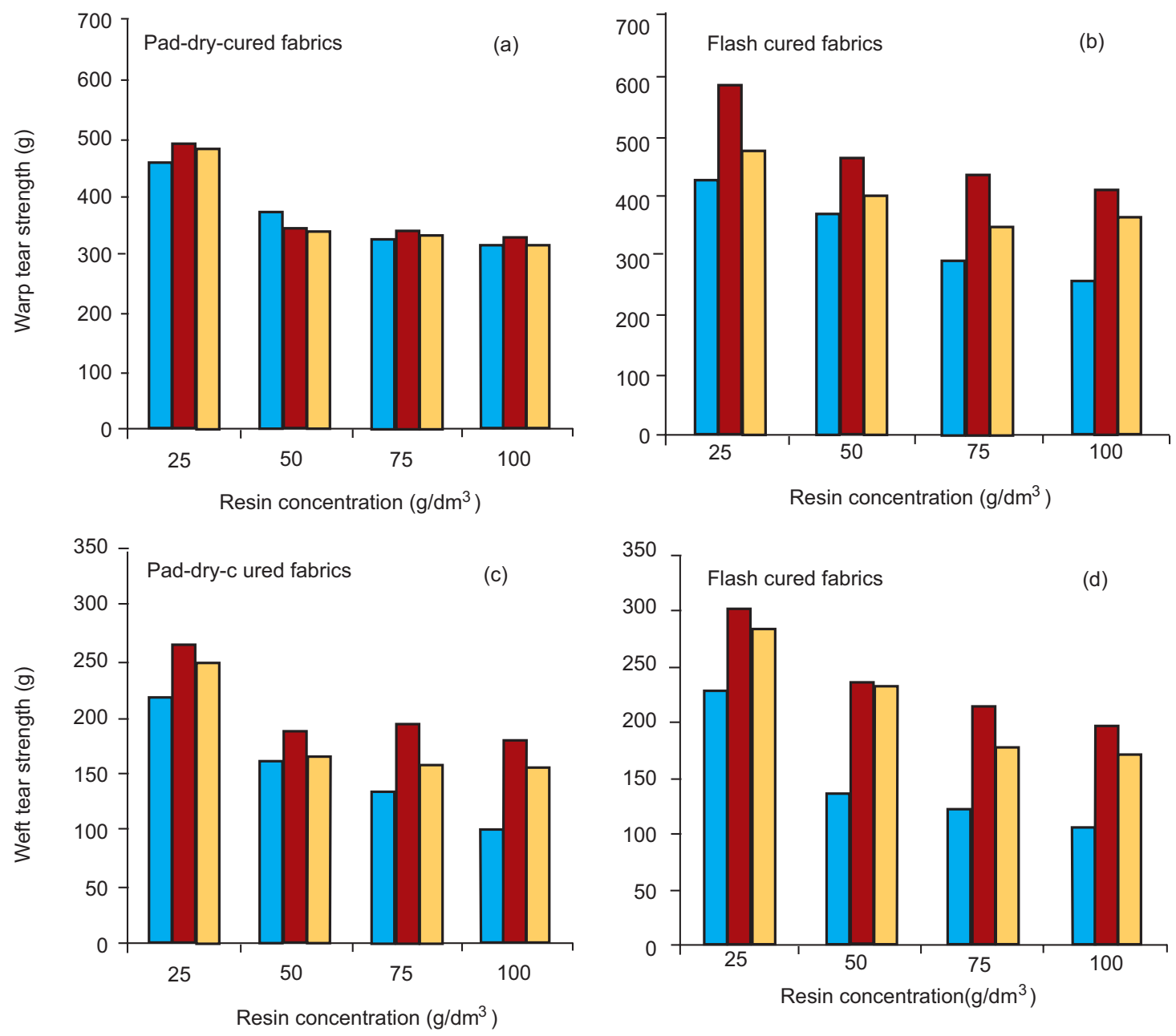

Protorez R arkofix NZF Protorez R/ Arkofix NZF

Fig. 4a-d. Tear strength values (g) of 1 time washed fabrics Vs resin concentration $\left(\mathrm{g} / \mathrm{dm}^{3}\right)$; (a) warp tear strength (g) values of pad-dry-cured fabrics, (b) warp tear strength (g) values of flash cured fabrics, (c) weft tear strength $(\mathrm{g})$ values of pad-dry-cured fabrics, (d) weft tear strength $(\mathrm{g})$ values of flash cured fabrics.
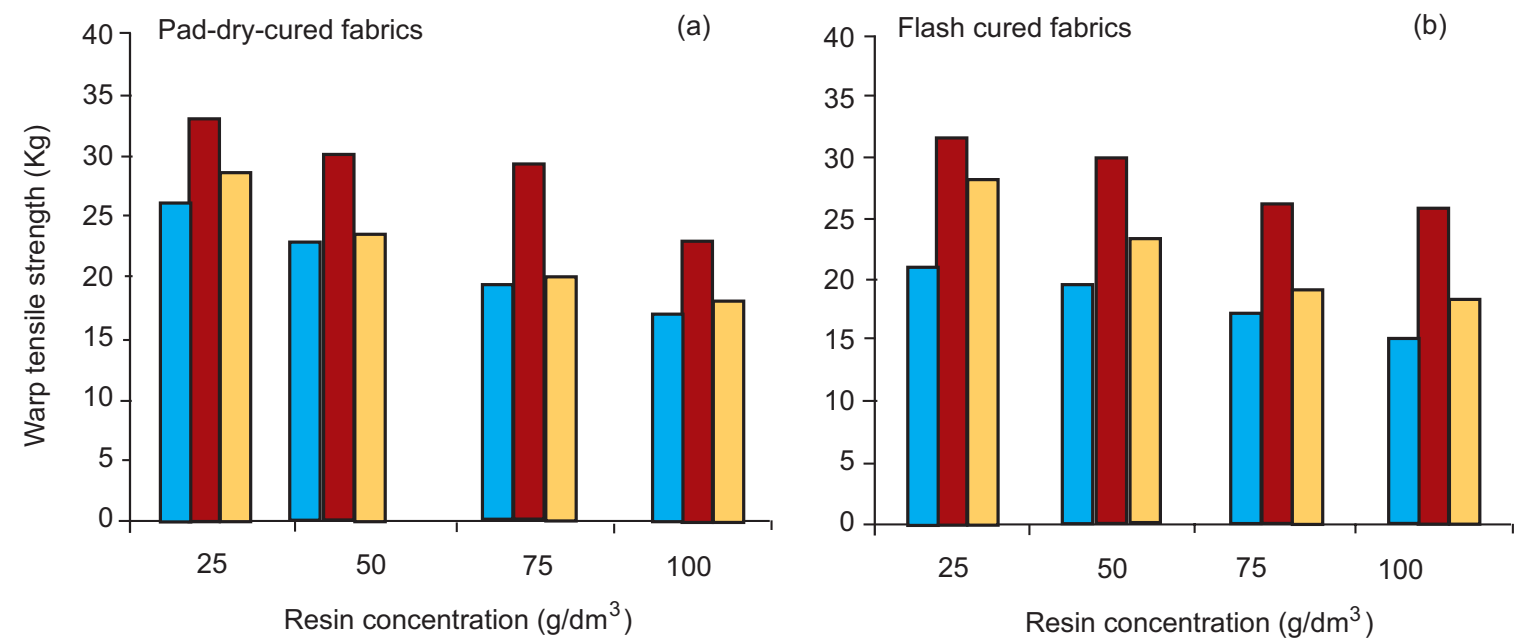

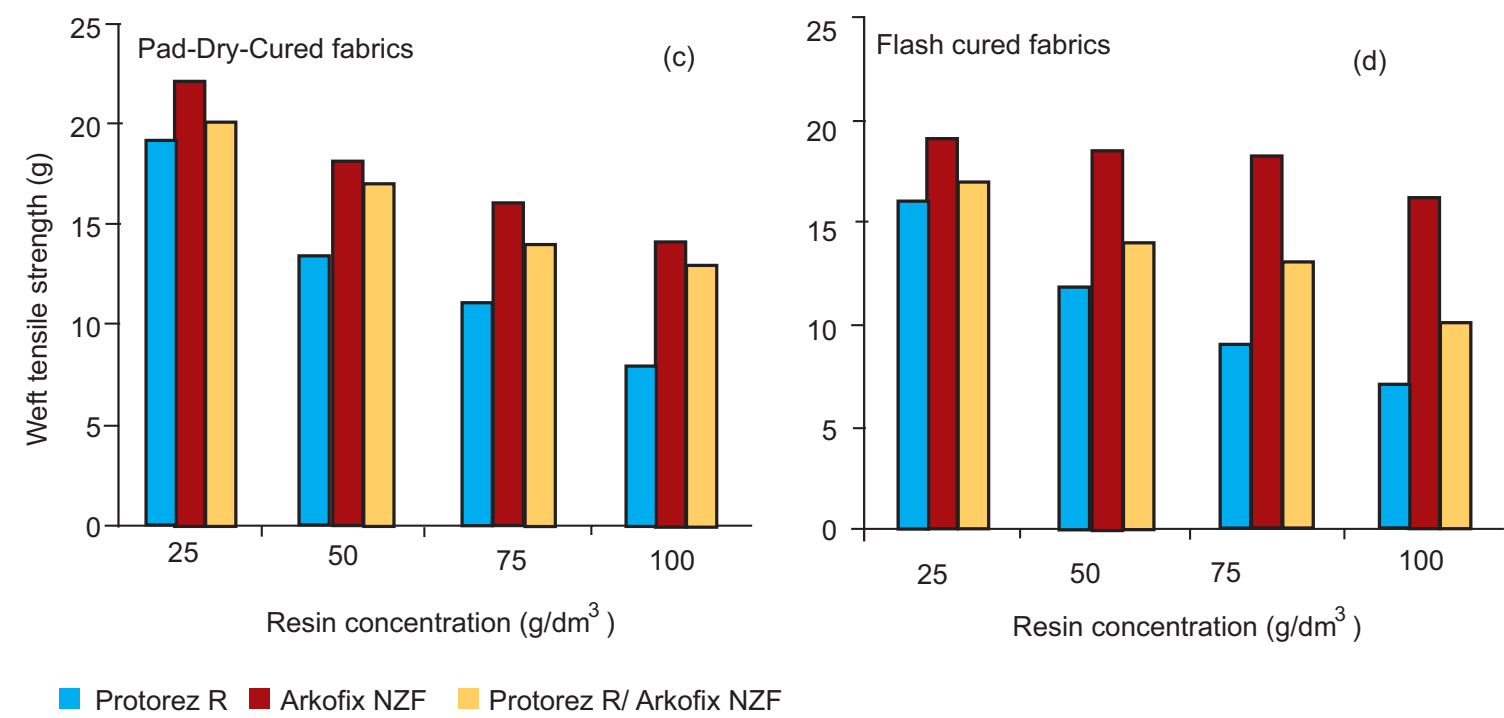

Fig. 5a-d. Tensile strength values $(\mathrm{kg})$ of 1 time washed fabrics Vs resin concentration $\left(\mathrm{g} / \mathrm{dm}^{3}\right)$; (a) warp tensile strength $(\mathrm{kg})$ values of pad-dry-cured fabrics, (b) warp tensile strength $(\mathrm{kg})$ values of flash cured fabrics, (c) weft tensile strength $(\mathrm{kg})$ values of pad-dry-cured fabrics, (d) weft tensile strength $(\mathrm{kg})$ values of flash cured fabrics.

NZF resins combination was improved as compared to the appearance of fabrics treated with Arkofix NZF resin alone due to the formation of interchain crosslinks formed by Protorez $\mathrm{R}$ resin.

\section{Conclusion}

Crosslinking of cotton fabric has been carried out to completion in a single stage flash cure process and conventional pad-dry-cure process using conventional crosslinkers Protorez R and Arkofix NZF. Evaluation of crease recovery angle, tear and tensile strength properties of cotton fabric finished by two techniques show that better tear and tensile strength values are obtained by flash cured fabrics without any adverse effect on crease recovery angle values. The results of the work are also consistent with the hypothesis that intermolecular crosslinking of neighbouring chains is the dominant mechanism in improving the crease recovery of cotton fabric. Furthermore, the subsequent drying and afterwash can be omitted to save energy used in conventional finishing operations.

\section{References}

Ferrero, F., Periolatto, M., Sangermano, M., Songia, M.B. 2008. Water repellent finishing of cotton fabrics by ultraviolet curing. Journal of Applied Polymer Science, 107: 810-818.

Gagliardi, D.D., Gruntfest, I.J. 1950. Creasing and crease proofing of textiles. Textile Research Journal, 20: $180-188$.

Gonzales, E.J., Reinhardt, R.M. 1986. Foam finishing treatment of cotton fabrics with formaldehyde. Part I: Textile physical properties. Textile Research Journal, 56: 497-502.

Gonzales, E.J., Benerito, R.R., Berni, R.J. 1966 a. Kinetics of the reactions of ethylene urea derivatives with cotton cellulose, Part I: The cellulose-dihydroxy ethylene urea reaction. Textile Research Journal, 36: 565-571.

Gonzales, E.J., Benerito, R.R., Berni, R.J., Zacharis, H.M. 1966b. Kinetics of the reactions of ethylene urea derivatives with cotton cellulose, Part II: The cellulose-dimethylol dihydroxy ethylene urea reaction. Textile Research Journal, 36: 571-578.

Lambert, A.H., Harper, R.J. 1990. Single side crosslinking via foam finishing to produce garment dyeable cotton fabrics. Journal of Industrial Textiles, 19: $169-180$.

Marsh, J.T. 1966. An Introduction to Textile Finishing. 432 pp. $2^{\text {nd }}$ edition, Chapman and Hall, London, UK.

Millington, K. 1998. Using ultraviolet radiation to reduce pilling of knitted wool and cotton. Textile Research Journal, 68: 413-421.

Mukhopadhyay, A., Midha, V.K. 2008. A review on designing the waterproof breathable fabrics, 
Part I: Fundamental principles and designing aspects of breathable fabrics. Journal of Industrial Textiles, 37: 225-262.

Namboodri, C.G., Duke, M.W. 1979. Foam finishing of cotton containing textiles. Textile Research Journal, 49: 156-162.

Pensa, I.E., Sello, S.B. 1982. Energy conservation technique in durable press finishing. Textile Research Journal, 52: 335-343.

Petersen, H. 1968. Reaction mechanism, structure, and properties of methylol compounds in cross-linking cotton. Textile Research Journal, 38: 156-176.

Reinhardt, R.M., Harris, J.A. 1980. Ultraviolet radiation in treatments for imparting functional properties to cotton textiles. Textile Research Journal, 50: 139-147.

Rollins, M.L., Carra, J.H., Gonzales, E.J., Berni, R.J. 1966. Microscopical comparisons of some reactions of cotton cellulose with ethylene derivatives. Textile Research Journal, 36: 185-201.

Rowland, S.P., Bertoniere, N.R., King, W.D. 1983a. Assessment of fabric performance versus reagent location from lick roller application of DMDHEU. Textile Research Journal, 53: 187-196.

Rowland, S.P., Bertoniere, N.R., King, W.D. 1983b.
Durable press performance and reagent distribution from foam application of DMDHEU. Textile Research Journal, 53: 197-204.

Steele, R. 1960. The relation of wet and dry crease recovery to wash wear behaviour. Textile Research Journal, 30: 37-46.

Stevens, C.V., Smith, B.F. 1970. Cross-linking reaction of cotton cellulose with ethylene urea derivatives; having varying hydrogen bonding capabilities, Part I: Effect on the physical properties and the hydrogen bonded structure. Textile Research Journal, 40: 749-760.

Varghese, J., Doshi, B.A. 1982. Durable press finishing of cotton drill using transfer-pad-cure technique. Textile Research Journal, 52: 638-643.

Wadsworth, L.C., Wey, P.S. 1988. Effect of differential foam application of durable press and fluorochemical finishes to cotton fabric. Journal of Industrial Textiles, 17: 152-166.

Weigmann, H.D., Scott, M.G., Rebenfeld, L. 1969. Relation of fibres and fabric properties in durable press cotton. Textile Research Journal, 39: 460-470.

Wright, E.L. 1981. Low wet pick-up finishing: A review of commercial experience. Textile Research Journal, 51: $251-255$. 